\title{
PARALISIA BILATERAL DO ABDUCENTE EM CARCINOMA DE NASOFARINGE
}

\author{
ANTONIO L. DOS SANTOS WERNECK * JOAO J. FREITAS DE CARVALHO * \\ ROBERTO C. PEREIRA DO PRADO*
}

RESUMO - Apresentamos um caso de paralisia bilateral do abducente camo achado inicial en carcinoma de nasofaringe. Discute-se o modo de envolvimento. Somente um caso semelhante fol registrado anteriormente na literatura.

Abducens bilateral palsy in nasopharyngeal carcinoma.

SUMMARY - We report a case of bilateral abducens palsy as initial finding in nasopharyngeal carcinoma. Possible mode of involvement is discussed. Only one case has been reported in the past.

Dentre as causas prováveis de paralisia bilateral do nervo abducente estão incluídas a hipertensão intracraniana, o aneurisma carotídeo intracavernoso, a polineuropatia craniana idiopática e a sindrome de Guillain-Barré. O carcinoma da nasofaringe comumente invade nervos cranianos, sendo o abducente um dos preferidos. No entanto, o comprometimento do nervo ocorre de forma unilateral e, geralmente, acompanhando outros sinais e sintomas próprios ao tumor.

Tivemos a oportunidade de examinar um paciente cujo achado clínico inicial foi paralisia bilateral do adbucente. Em revisão da literatura mundial encontramos apenas publicação de um caso semelhante 1 . O caso do paciente observado por nós é aqui relatado.

\section{OBSERVACAOO}

MRS, paciente do sexo masculino, com 58 anos de idade (registro HaE 612742), internado com história de cefaléia occipito-frontal há 8 meses. Visão dupla horizontal surgiu dois meses após o início da cefaléia. Relata perda de $6 \mathrm{Kg}$ nos últimos dois meses. Tabagista inveterado. A ectoscopia mostrava paciente emagrecido, com muccsas hipocoradas. $O$ restante dc exame clínico era normal. o exame neurológico mostrava, bilateralmente, paresia do VI nervo craniano. No restante, o exame neurologico era normal. Punçáo lombar evidenciou líqüido cefalorraqueano (LCR) de aspecto claro, com pressăo injelal de $7,8 \mathrm{~cm}$ H20 e apresentando: 1,0 células $/ \mathrm{mm} 3$, proteínas $74 \mathrm{mg} 7 \mathrm{dl}$ e glicose $56 \mathrm{mg} / \mathrm{dl}$, Exames laboratoriais: hemograma e bioquimica normais. Tomografia simples de teto de cavum (Fig. 1) evidenciou erosão no corpo do esfenoide, no assoalho selar e nas extremidades proximais dos rochedos temporais. Tomografia computadorizada de crânio (Fig. 1) mostrou ventrículos de tamanho normal e massa hiperdensa na base do crânio ao nivel do clivus. A rinoscopia posterior mostrou abaulamento da parede postero-lateral do cavum, recoberto por mucosa. Biópsia nesta regiăo demonstrou tratar-se de carcinoma epidermóide pouco diferenciado. $O$ paciente foi submetido a radioterapla associada a corticoterapia, mas veio a falecer alguns meses após.

* Servico de Neurologia, Hospital dos Servidores do Estado do Rio de Janelro (HSE). 

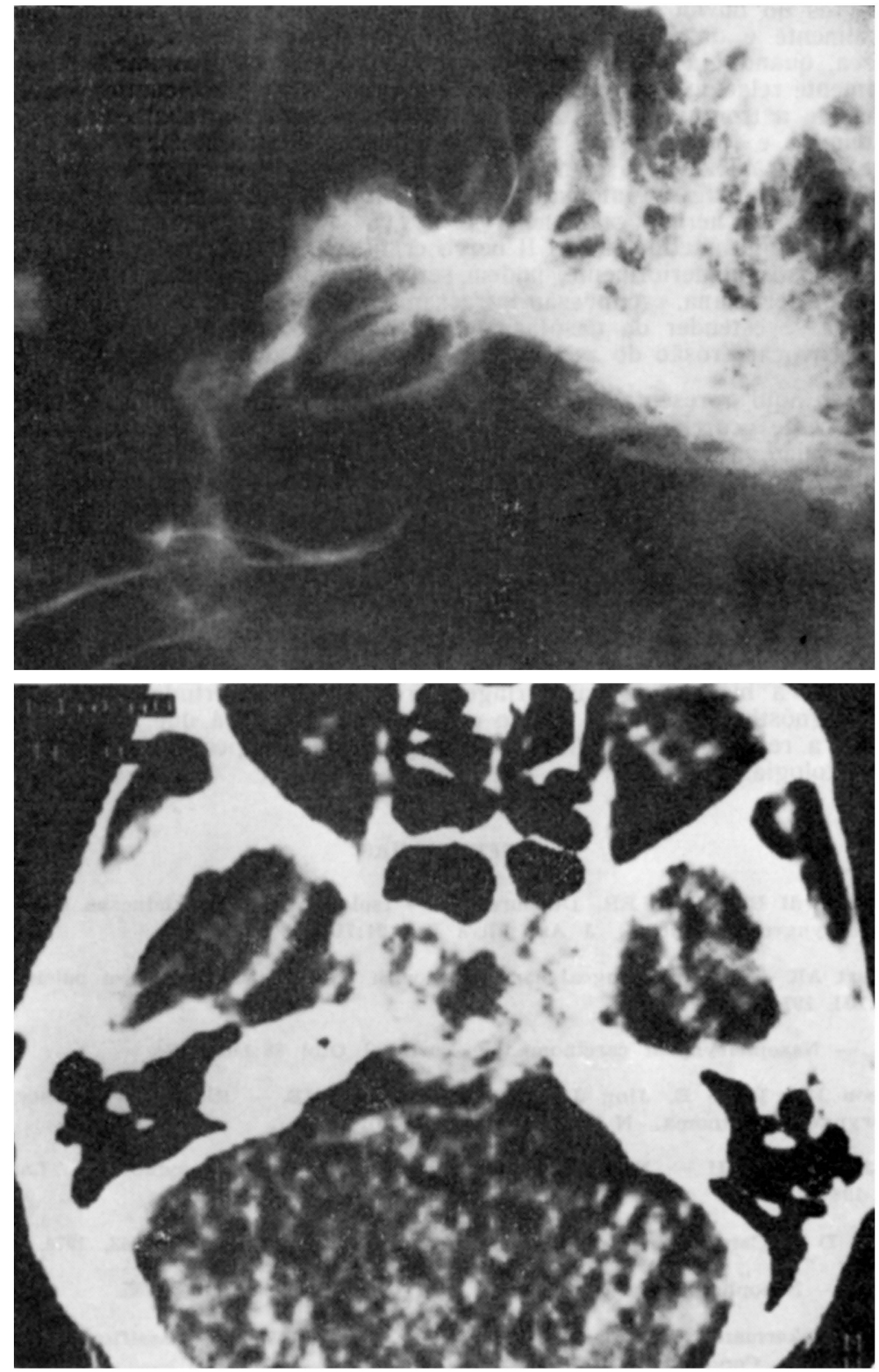

Fig. 1 - Caso MRS. No alto, tomografia simples do teto do cavum evidenciando erosão no corpo do esfenóide, no assoalho selar $e$ nas extremidades proximais dos rochedos. Em baixo, tomografia computadorizada do cranio mostranndo massa hiperdensa na base do cranio ao nivel do clivus. 


\section{COMENTARIOS}

O carcinoma de nasofaringe não é tumor raro, constituindo $8 \%$ de todas as lesões malignas do ouvido, nariz e garganta 3 . No entanto, por causa de sua localização, geralmente é diagnosticado após sua palpação no pescoço ou provocar destruição óssea, quando já se encontra bastante aumentado de volume. A nasofaringe está intimamente relacionada com os forames da base de crânio, com o seio esfenoidal, a fossa nasal e a trompa de Eustaquio. Numa análise dos trabalhos de McCallum 6, Matz e Conner 5 e Perez et al.8 sobre a freqüência dos sintomas de carcinoma da nasofaringe, verificamos que o primeiro achado seria a presença de massa no pescoço, seguido de surdez, otalgıa, sintomas nasais (obstrução e epistaxe) e, finalmente, sintomas unilaterais de nervos cranianos (V e VI). Quando o tumor se estende para a órbita, existe comprometimento do II nervo craniano. Os nervos cranianos VIl e XII, que se situam mais posteriormente, podem ser envolvidos nos estágios mais avançados de extensão intracraniana. A invasão intracraniana é feita através do foramen lacerum. O tumor pode se estender da nasofaringe até o crânio, numa distância de um centímetro, sem provocar erosão do assoalho da fossa média demonstrado radiologicamente.

No caso aqui apresentado, tivemos como achado singular o fato de ter a paralisia do abducente ocorrico de forma bilateral e como achado sintomatológico inicial. Em nossa opinião, a causa desta evolução incomum deveu-se a invasão simultânea cu quase que simultânea da fossa média em suas divisōes direita e esquerda. A possibilidade de compressão unilateral do VI nervo e paralisia contralateral por hipertensão intracraniana nos parece improvável, pois nosso paciente apresentava pressão do LCR normal e ausência de edema de papila na fase inicial. Outro aspecto importante a ser analisado é o de que a primeira rinoscopia foi dada como nornal, fato para o qual Pang 7 já tinha chamado atenção. Preconivaza ele a necessidade de repetidas biópsias uma vez suspeia a patologia, além de considerar o não constatar a patologia pela palpação, um dado insuficiente para afastar o diagnóstico. Esta discussāo sobre a biópsia de nasofaringe é relevante em virtude da necessidade de se fazer o diagnóstico diferencial com o cordoma de clivus, já que não raramente este tumor invade a região da nasofaringe e $n$ aspecto radiológico pode ser o mesmo em ambas as patologias.

\section{REFERENCIAS}

1. Bomb BS, Bedj HK, Vyas BR, Deypura JC - Isolated bilateral abducens nerve paralysis in nasopharyngeal carcinoma. $J$ Ass Phys Ind 24:719, 1976.

2. Chakrabart AK - Nasopharyngeal carcinoma with multiple cranial nerve palsies. Practioner $212: 103,1974$.

3. Choq G - Nasopharyngeal carcinoma. J Laringol Otol $88: 145,1974$.

4. Henderson LE, Lovie E, Jing JS, Buel P, Garoner MB - Risk factcrs associated with nasopharyngeal carcinoma. N Engl J Med 295:1101, 1974.

5. Matz CJ, Couner GH - Nasopharyngeal carcinoma: signs and symptoms. Iaryngoscope $78: 1763,1968$.

6. MeCallum D - Carcinoma of the nasopharynx. J Laringol Otol 88:843, 1974.

7. Pang LQ -.. Nasopharyngeal carcinoma. Arch Otolaryngol 88:622, 1955.

8. Perez CA, Ackerman LY, Mill WB, Ogura JH, Powers WE - Classification of nasopharyngeal cancer. Cancer $24: 1,1969$.

9. Silver AJ - Computed tomography of the nasopharynx and related spaces. Radiology $147: 733,1983$. 